\title{
Evacuation Experiment Study in Up and Down Escape Staircase of Underground Road
}

\author{
Da-jun Yuan, ${ }^{1}$ Hui Jin ${ }^{(D,}{ }^{1}$ Zhi-cong Chen, ${ }^{2}$ and Sheng-nan Liu ${ }^{1}$ \\ ${ }^{1}$ School of Civil Engineering, Beijing Jiaotong University, Beijing 100044, China \\ ${ }^{2}$ Xiamen Rail Transit Group Limited Corporation, Xiamen 361004, China \\ Correspondence should be addressed to Hui Jin; 17115308@bjtu.edu.cn
}

Received 13 June 2020; Revised 20 February 2021; Accepted 8 March 2021; Published 19 March 2021

Academic Editor: Wen-Chieh Cheng

Copyright (c) 2021 Da-jun Yuan et al. This is an open access article distributed under the Creative Commons Attribution License, which permits unrestricted use, distribution, and reproduction in any medium, provided the original work is properly cited.

To measure evacuation basic parameters, reveal evacuation performance, and study reasonable staircase spacing of up and down escape staircase in case of fire, an evacuation experiment, which was based on the most unfavorable evacuation scenario, was conducted. The experiment took personnel and vehicles of actual underground road traffic into account, and evacuation process image data were extracted and analyzed by artificial statistics. Experimental results indicate that the personnel plane evacuation speed is between 1.43 and $1.95 \mathrm{~m} / \mathrm{s}$, and the upstairs evacuation speed that is less affected by gender and age is mainly between 0.5 and $1.1 \mathrm{~m} / \mathrm{s}$; under the escape stairs width of $0.8 \mathrm{~m}$, the average capacity of escape staircase is $0.7 \mathrm{P} / \mathrm{s}$, and the entrance of the staircase is evacuation bottleneck and queuing phenomenon occurs. Based on the experiment, a calculation model of three-phase personnel net evacuation time was established. By simplifying the evacuation model, a calculation formula of the reasonable escape stair spacing considering the influence of multiple factors was proposed. And the proposed theoretical model was verified by project cases of up and down escape staircase. With 2 min emergency broadcasting time and 6 min Available Safety Evacuation Time of medium-sized fire as the Personnel Safety Evacuation Rule's reference, the recommended value of escape staircase spacing of single pipe double-deck two-way four-lane (double pipes double-deck two-way eight-lane) underground roads is $64.3 \mathrm{~m}$.

\section{Introduction}

As the greatest security threat during the operation period, tunnel fire causes incalculable loss of life and property and also brings about a great negative social impact. Urban underground roads usually have the characteristics of dense traffic, large human loads, numerous entrances, and exits, and so on, which are different from ordinary road tunnels. Reasonable and effective evacuation escape channel arrangement is a prerequisite for the personnel's autonomous rescue and a necessary condition for professional firefighting rescue in the underground road fire.

Evacuation in the up and down escape staircase of the tunnel is a new evacuation pattern introduced with the emergence of the double-deck shield tunnel. At present, the traffic tunnel fire protection technology specification has not yet provided provision for escape stairs function requirements, which means that the standardized design of escape staircases lacks a unified basis. Although the Shanghai Municipal Provincial Standard "Road Tunnel Design Code"(2008) [1] recommends that the escape stairs spacing should be controlled within $120 \mathrm{~m}$, the width of stairs is not less than $0.8 \mathrm{~m}$, and the maximum capacity of personnel is $1.0 \mathrm{P} / \mathrm{s}$, but there is still no supporting theoretical and actual verification.

Reasonable escape stairs spacing was mainly studied by numerical simulation and on-site evacuation test. Some scholars established specific fire evacuation model scenarios through the joint simulation of fire field numerical simulation software such as FDS and personnel evacuation simulation software such as STEPS, Simulex, and EVACNET, and according to the specific engineering background, the prediction of the safety evacuation time, the safety check calculation of the escape channel spacing, and the optimization of the personnel evacuation strategy were carried out. Researches showed that the recommended escape stairs spacing is between 80 and $100 \mathrm{~m}$ [2-5]. 
Numerical simulation cannot reflect the real evacuation behavior and evacuation characteristics. Therefore, some scholars have carried out some on-site evacuation simulation tests to make up for the defects and deficiencies of computer numerical simulation. The attention was firstly paid to the personnel's behavior evacuation characteristics, evacuation signs, and other facilities on the choice of personnel escape exits under fire conditions $[6,7]$. In recent years, some scholars investigated the characteristics of road walking speed in a full-scale tunnel filled with smoke [8-10], and Zhang et al. [11] conducted evacuation experiments to examine the movement speed and evacuation capacity in an underwater shield road tunnel with different vertical exits. In addition, some scholars focused on evacuation characteristics of escape slides [12, 13] and horizontal corridors outdoor trials $[14,15]$. But most of the existing physical personnel evacuation tests focused on the characteristics of personnel evacuation behavior, the escape exit selection, and the effectiveness of escape exit signs. However, the relationship between evacuation characteristics and escape stairway spacing has not been systematically studied, and there is still no theoretical design basis for the reasonable escape staircase spacing.

To solve these problems, an evacuation experiment based on the most unfavorable evacuation scenario was conducted. A calculation model of three-phase personnel net evacuation time was established. Finally, a calculation formula of the reasonable escape stair spacing considering the influence of multiple factors was proposed. Results will contribute to providing scientific guidance for the design of up and down escape stairs.

\section{Personnel Safety Evacuation Rule}

ASET (Available Safety Evacuation Time) and RSET (Required Safety Evacuation Time) are two key indicators for assessing whether people can evacuate safely in a fire incident. ASET is defined as the time for a fire to develop into a direct threat to a person, and RSET is defined as the time that a person flees to the safe area. Engineering disaster prevention system and requirements for safe evacuation require that all personnel in the tunnel can evacuate to the safe area before the fire reaches a dangerous state, i.e., ASET $>$ RSET [2]. Personnel Safety Evacuation Rule is shown in Figure 1.

According to the analysis of foreign tunnel data and fire accident cases, if the ventilation, firefighting, emergency lighting system, and other systems in the tunnel are working normally, the safe evacuation time is generally within 15 minutes, while a medium-scale fire $(20 \mathrm{MW})$ occurs during the normal operation phase. "Road Tunnel Design Code" recommends that personnel safety evacuation time RSET should be less than $15 \mathrm{~min}$. In the evacuation simulation study of the Shanghai Yangtze River Tunnel using STEPS, Cao and Shen [16] found that smoke can not be controlled assumingly beyond 6 minutes under a medium-scale fire. In the optimization analysis of the highway tunnel escape stair spacing under the lane plate, Zhang et al. [3] used 6 minutes as ASET referring to the "Metro Design Code," and "Beijing
East Second Ring Underground Road Disaster Prevention Design Standard" also stipulates that ASET is 6 minutes.

As shown in Figure 2 the evacuation process is divided into the following three main time nodes according to the measurability of evacuation time.

2.1. Alarm Time $t_{1}$. Alarm Time $t_{1}$ refers to the time that personnel was informed of fire intelligence. PIARC research report showed that the alarm time for general-level manual control tunnels is 2 to 5 minutes, and the city's underground road safety level is usually much higher. Therefore the alarm issued time is shorter than the average manual control tunnels. For example, the alarm program designed by the Shanghai Yangtze River Fire Alarm System can be confirmed and started within 2 minutes [15].

2.2. Hesitation and Reaction Time $t_{2}$. The time required for a person to respond to an emergency broadcast until they get off transport is $t_{2}$. This part of the time can be divided into two parts. According to the observation data of Noren and Winer [17], after the release of the emergency broadcast, the hesitation time of the personnel in the vehicle, which is as the first part, is usually within 1.5 minutes and the individual differences are large. The time that the people hear the clear alarm and decide to get off the transportation is the second part, and the relevant scholars found that the second part of $t_{2}$ is $15 \mathrm{~s}$ after conducting a field test as the time required to personnel respond to emergency broadcasts until they get off, $t_{2}$ can be determined to be $105 \mathrm{~s}$.

2.3. Net Evacuation Time $t_{3}$. The time that personnel flees to a nonfire tunnel or traffic layer is $t_{3}$, and it refers to the time required for the last stayer to arrive at the exit of the evacuation passage. The net evacuation time of the crowd is affected by factors such as the distance of the tunnel escape stairs, the characteristics of crowd evacuation, and individuals.

The estimated value of the complete evacuation time of the underground road after a fire is given by equation (1). It can be judged whether there is a security threat to evacuation by comparing the complete evacuation time with ASET.

$$
T=t_{1}+t_{2}+t_{3} \leq \mathrm{ASET},
$$

where $T$ is the required safety evacuation time, which consists of $t_{1}, t_{2}$, and $t_{3}$ and is requested T $\leq$ ASET [2].

To guide the design of the tunnel disaster prevention system, the relationship between the net evacuation time and the distance between the tunnel escape stairs and the capacity of the stairs must be established.

\section{Personnel Evacuation Test}

3.1. Evacuation Test Platform for Escape Staircase. A personnel evacuation test was carried out in the underground traffic connection channel of a double-hole tunnel in Tongzhou New Town, Beijing. The double-hole tunnel with a length of $1.2 \mathrm{~km}$ contains six straight-through escape stairs. 


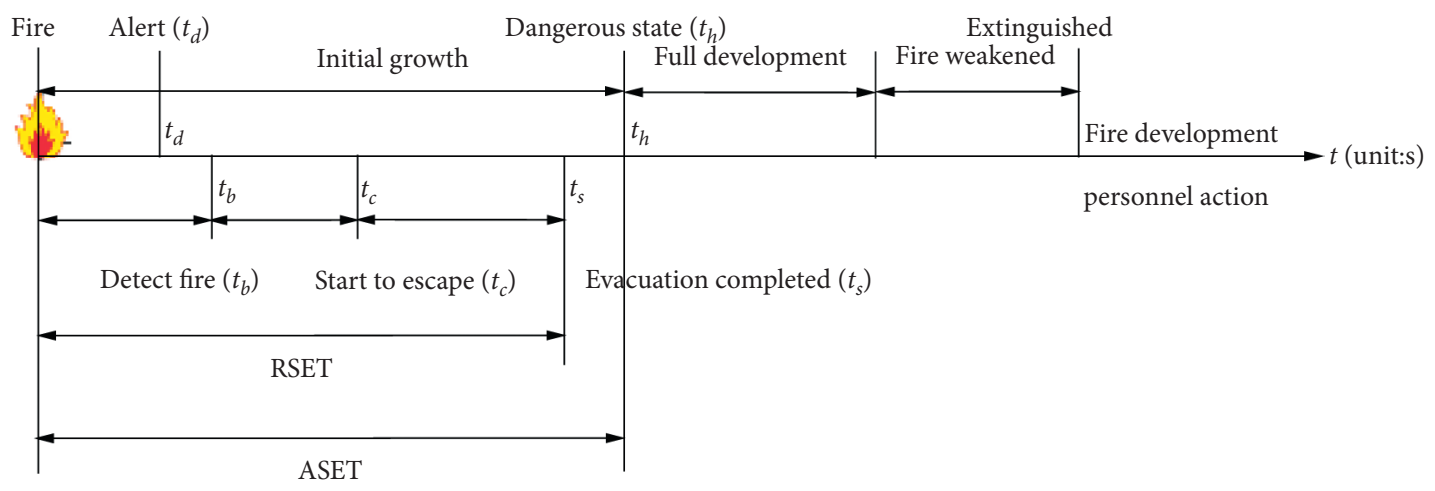

FIgure 1: Personnel safety evacuation rule [2].

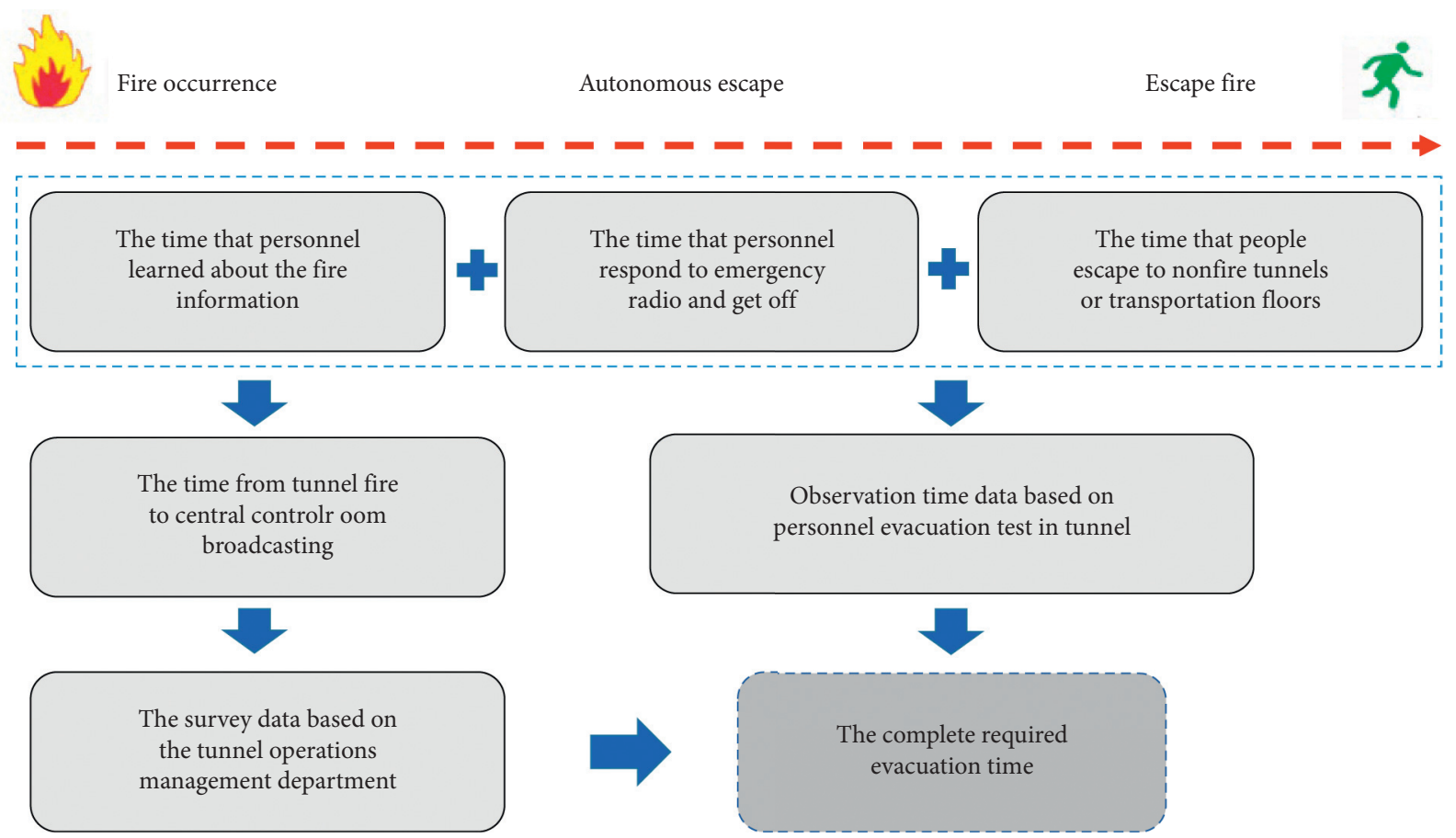

FIgURE 2: Resolution of personnel evacuation node time.

The test section of the tunnel is $400 \mathrm{~m}$ long, starts at $K 1+500$, and ends at $K 1+100$. The escape staircase at $K 1+450$ was selected as the evacuation exit.

A test scene was set up with enclosures in the first two escape stairs and in the middle platform, as shown in Figure 3. Stair enclosures were constructed by splicing a $1.8 \mathrm{~m}$ high retaining wall. According to "Road Tunnel Design Code," evacuation indicators were placed on the wall at the corner of the escape staircase. The construction of the test escape staircase and the typical double-deck escape staircase was shown in Table 1.

The test section simulates the traffic conditions of two lanes for cars with a width of $3.5 \mathrm{~m}$, and the vehicle parking distance is $1.5 \mathrm{~m}$. As shown in Figure 4, at the exit of the near escape $(K 1+400$ to $K 1+450), 10$ physical vehicles entering and 6 simulated vehicles were parked at a set interval of $1.5 \mathrm{~m}$, and the rest of the road $(K 1+300$ to $K 1+400$, $K 1+450$ to $K 1+500$ ) was equipped with simulated vehicles at the same interval of $1.5 \mathrm{~m}$. The size of the simulation vehicle is $4.5 \mathrm{~m} \times 1.8$, and the physical vehicles include 2 minivans, 5 small cars, $1 \mathrm{SUV}$, and 2 commercial vehicles. The fullness factor cars were selected as $0.5 \sim 1$ (Full number is 4$)$.

3.2. Testing Personnel. Participants were required to be in a good physical condition and have no experience of driving on underground roads, fire evacuation drills in tunnels, and being firefighters or fire engineers. To avoid the influence of "Learning Effect" and ensure test results were satisfactory, specific details, such as the site environment, tunnel layout, emergency exit location, test content, and process, etc., were not informed to participants.

The number of experimenters was determined by the number of vehicles deployed within a $50 \mathrm{~m}$ escape distance and the fullness factor. In this experiment, 40 people (32 


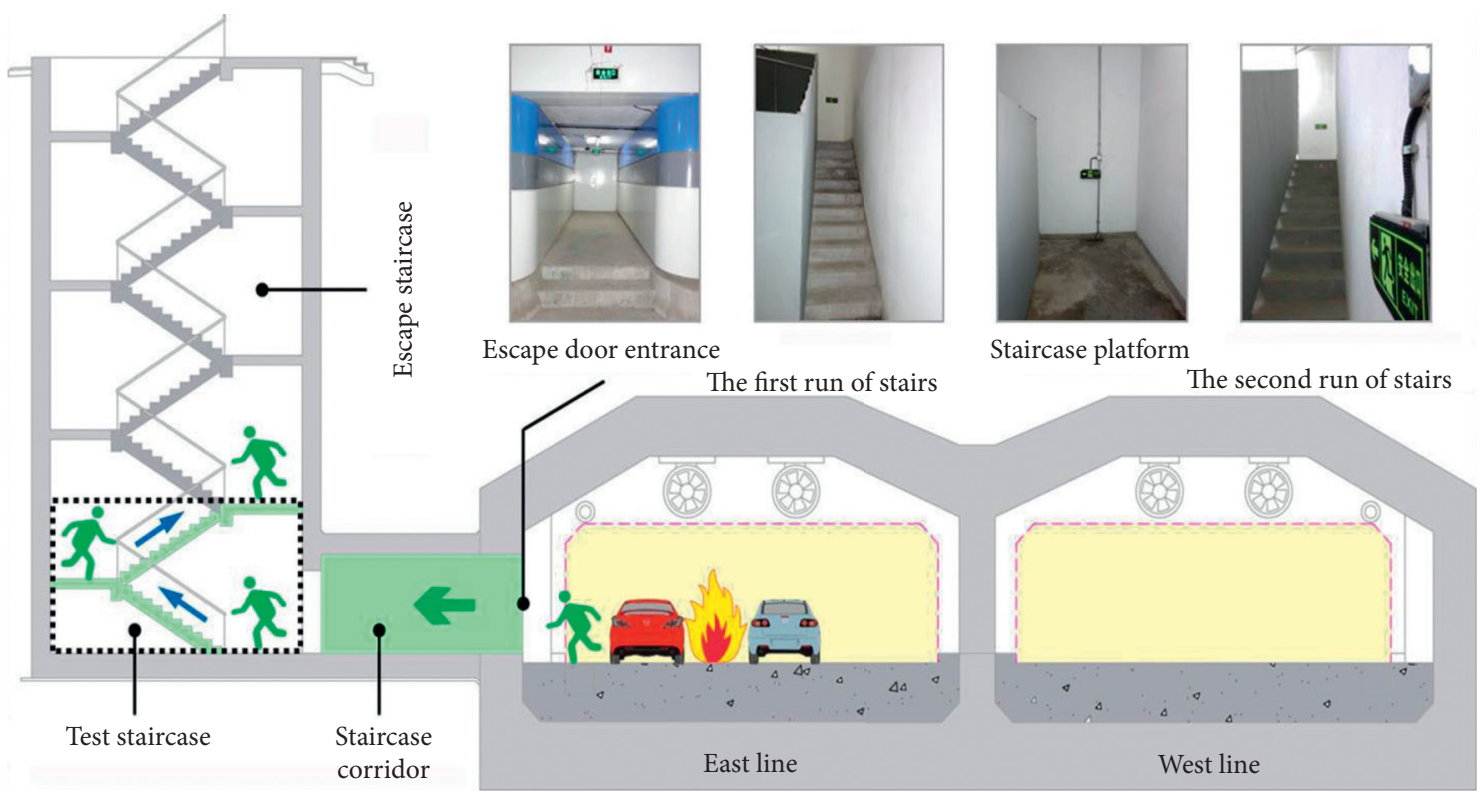

FIGURE 3: Form of escape staircase in the experiment.

Table 1: Comparison between experiment escape staircase and the Nanjing Weisan Road Tunnel's.

\begin{tabular}{lcccc}
\hline Project & Stair width $(\mathrm{m})$ & Stair angle & Stairs stepping $(W \times H)$ & Staircase formation \\
\hline Test stairs & 0.8 & $30^{\circ}$ & $170 \mathrm{~mm} \times 280 \mathrm{~mm}$ & $(10+10)$ steps $+2.0 \mathrm{~m}$ middle platform \\
Typical stairs & 0.8 & $30^{\circ}$ & $151 \mathrm{~mm} \times 267 \mathrm{~mm}$ & $(9+17)$ steps $+1.2 \mathrm{~m}$ middle platform \\
\hline
\end{tabular}

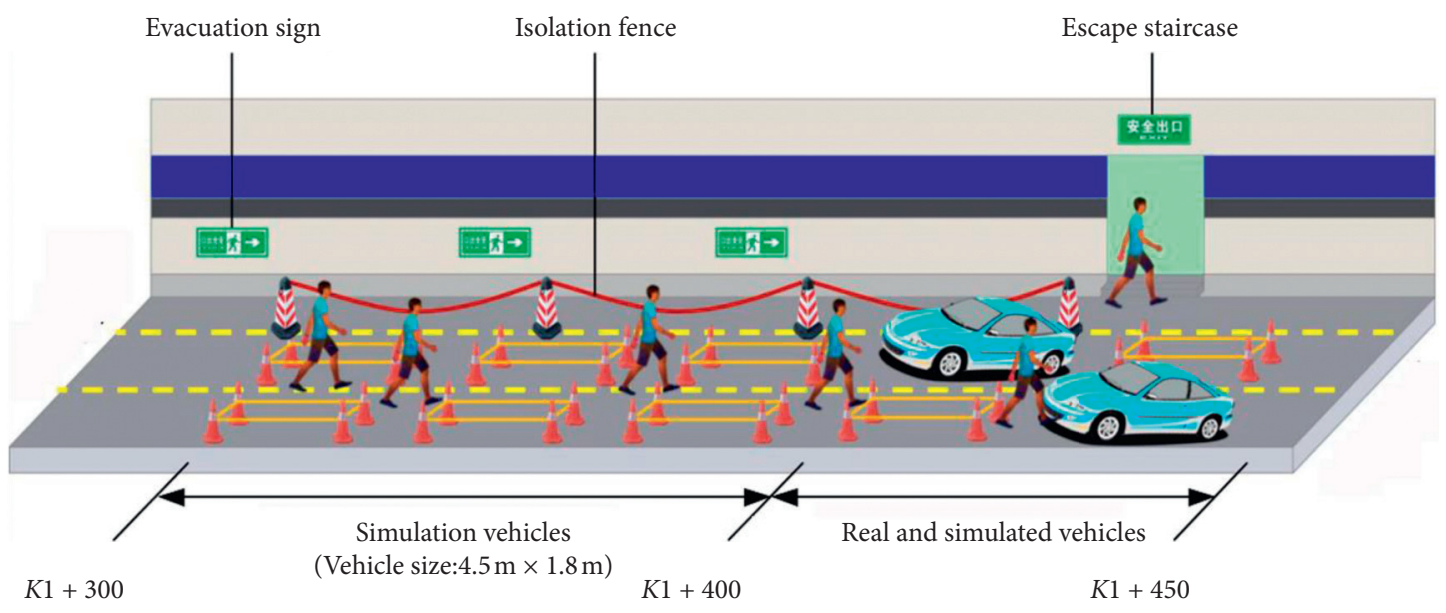

FIGURE 4: Evacuation scenario arrangement of the tunnel.

men and 8 women) participated in the evacuation test, as shown in Table 2 and Table 3. Some of the people brought bags into the venue to get closer to the real evacuation scenarios.

3.3. Image Acquisition. Video capture guns numbered $\mathrm{C} 1$ to $\mathrm{C} 4$ were arranged in the tunnel test section at an interval of $50 \mathrm{~m}$. In addition, two hemispherical cameras numbered C5 and C6 were, respectively, arranged in the front room of escape stairs and the exit of the escape section to record the time for the staff to go upstairs.
TABLE 2: Form of experiment participants' source.

\begin{tabular}{lcc}
\hline Source & Number & In total \\
\hline College students & 13 & \\
People work in designing institute & 12 & 40 \\
Security personnel & 15 & \\
\hline
\end{tabular}

3.4. Test Conditions and Progress. The most unfavorable evacuation situation under normal traffic conditions is as follows: the ignition point was located at an entrance of an escape staircase, which made the exit unusable and vehicles behind the fire stop. Therefore, all personnel within the 
TABLE 3: Form of experiment participants' type.

\begin{tabular}{lcc}
\hline Age & Male ratio (\%) & Female ratio $(\%)$ \\
\hline $17 \sim 29$ & 25 & 10 \\
$30 \sim 50$ & 32 & 5 \\
$>50$ & 23 & 5 \\
\hline
\end{tabular}

range from the ignition point to the upstream nearby available escape stairs (defined as the first range of escape spacing) evacuated to that stair exit available, as shown in Figure 5. Based on this most unfavorable evacuation situation, the evacuation of personnel was studied at the escape spacing of three groups of $50 \mathrm{~m}, 100 \mathrm{~m}$, and $150 \mathrm{~m}$.

During the test, as shown in Figure 4 and 5, 40 test personnel were randomly distributed on both sides of the door of physical vehicles or model vehicles in the corresponding working area, and the commander held the loudspeaker and continuously issued an evacuation broadcasting instruction of "A fire broke out in the front tunnel, please get off and evacuate imminently!" At the same time, traffic lights in the tunnel were switched to "no traffic". In addition, both the main tunnel and the escape stairwell were fully illuminated, and all people were evacuated in accordance with evacuation signs on sidewalls to the rear escape exit. To simplify the movement trajectory of the personnel and facilitate the extraction of the movement parameters of the people, the clustering behavior in the natural evacuation was not considered [7]. It assumed that the people in the same car were independent of each other and then escaped to the evacuation exit immediately after getting off, which would not form a family evacuation group. The net evacuation time was defined as the elapsed time from the issuance of the evacuation broadcast to the last stayer who went through the exit of the escape stair landing. Test screen images at different locations are shown in Figure 6.

\section{Observation Results of Evacuation Test}

4.1. Evacuation Speed of Personnel under Emergency. Figure 7 is a box distribution diagram of evacuation speed for different types of personnel on the pavement in the case of an escape interval of $50 \mathrm{~m}$. The coordinate axes M1 to M3 and $\mathrm{W} 1$ to $\mathrm{W} 3$ represent the male and female personnel in the age of $17 \sim 29,30 \sim 50$, and $51 \sim 80$, respectively. The measured value of the evacuation speed when the crowd walked on the road was between 1.43 and $1.95 \mathrm{~m} / \mathrm{s}$. The evacuation speed decreases with age for same gender testers; for the same age group, the evacuation speed of males was higher than that of females, except for participants aged 51-80 years old. The main reason is that there were only 2 females in this age group while 9 in men. Therefore, the observation data are scattered.

4.2. Evacuation Speed of People Going Upstairs in an Emergency. Figure 8 shows the change of evacuation speed of personnel going upstairs in an escape stairway. It can be seen from Figure 8 that the first few testers who entered the escape stairway have a faster speed of up to $1.1 \mathrm{~m} / \mathrm{s}$. At this time, congestion before the entrance of the stairs has not yet been formed and the traffic is smooth. When the number of people rushing into the entrance of escape stairs in unit time exceeds the actual capacity of the stairs, the failure to disperse the crowd timely will lead to crowds and large areas of backlog, and the staff will be close to each other and difficult to walk (i.e., crowd queuing), etc. Furthermore, the speed of personnel going upstairs drops dramatically, and the fluctuation is stable around $0.6 \mathrm{~m} / \mathrm{s}$. At this time, the upstairs speed tends to be the same, and there is little difference in the upstairs speed between different types of individuals.

4.3. Traffic Capacity of Escape Stairs. The relationship between the stair passing time and the number of people passing through the exit when the escape stair spacing is $50 \mathrm{~m}$ is shown in Figure 9. The time between when the first tester enters the escape stairway entrance and the last tester leaves the escape staircase exit is $61 \mathrm{~s}$ in total, which is called stair passing time. In addition, there is a significant linear correlation between the number of people passing and the passage time, which reflects that the evacuation speed of the pedestrians on the stairs is relatively constant and the interval between the individuals is uniform. Before the congestion at the stairs entrance occurs, the observed value of the average time occupied by personnel on the escape stairs is $7.0 \mathrm{~s}$. After the crowd queuing phenomenon appears, the average time is $12.5 \mathrm{~s}$, which shows that that the degree of blockage of the population has a significant impact on the length of the passage time.

Taking the continuous, uninterrupted flow of people at the exit of escape stairs as the research object, the observed value of the escape rate of escape stairs with a clear width of $0.8 \mathrm{~m}$ is about $0.7 \mathrm{P} / \mathrm{s}$, which is used to describe the escape capacity of stairs, and in this scenario, the personnel can only wait in line and go through the stairs exit one by one. In front of the entrance of the stairs, there is an evolutionary characteristic of people arriving, crowd backlogs, congestion alleviating and dissipating, and people evacuating to the target exit show a strong sense of competition, as shown in Figure 10. Therefore, how to optimize the escape stair spacing, reduce the queue waiting time and ensure the evacuation of the crowd in a safe time is critical to the optimizing of the tunnel design.

4.4. Net Evacuation Time. The net evacuation time of the three groups of different escape stair spacing and their composition were plotted as Figure 11. It can be seen from Figure 11 that the net evacuation time increases linearly as the escape stairs spacing increases, and the walking time on pavement and waiting time in line account for a large proportion. Furthermore, the waiting time for queuing decreases linearly with the increases of the escape stairs spacing, and the passage time on stairs is independent of the escape stair spacing. Therefore, increasing the escape stairs spacing reduces the waiting time so that the road travel time and the waiting time in the line achieve the optimal combination, which can increase the effective escape time and realize the optimized design of the tunnel. 


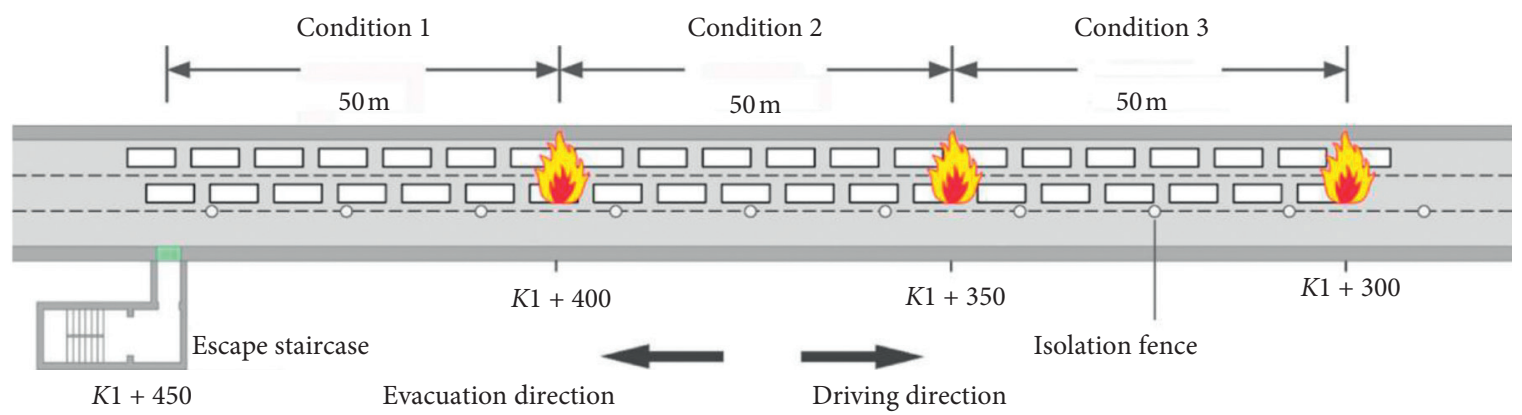

FIgURE 5: Evacuation experiment scenarios under different spacing of escape staircase.


FIGURE 6: Imagery pictures of evacuation.

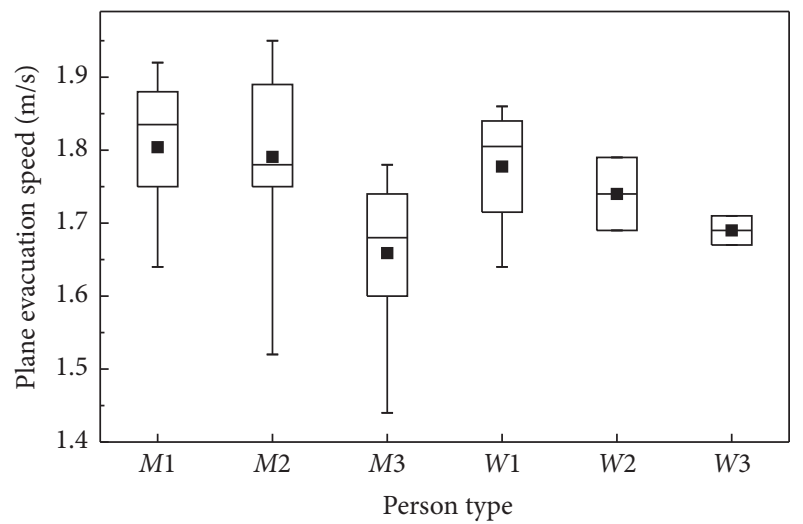

- Mean observation

Figure 7: Box figure of plane evacuation speed.

\section{Design Method of Escape Stair Spacing}

5.1. Calculation Model of Net Evacuation Time of the Personnel. Observing the last stayer, the progress of evacuation is divided into three stages: road evacuation, waiting in line, and staircase evacuation. The corresponding evacuation time is $t_{r}$ (the road evacuation time), $t_{w}$ (the waiting time in line), $t_{s}$ (the staircase evacuation

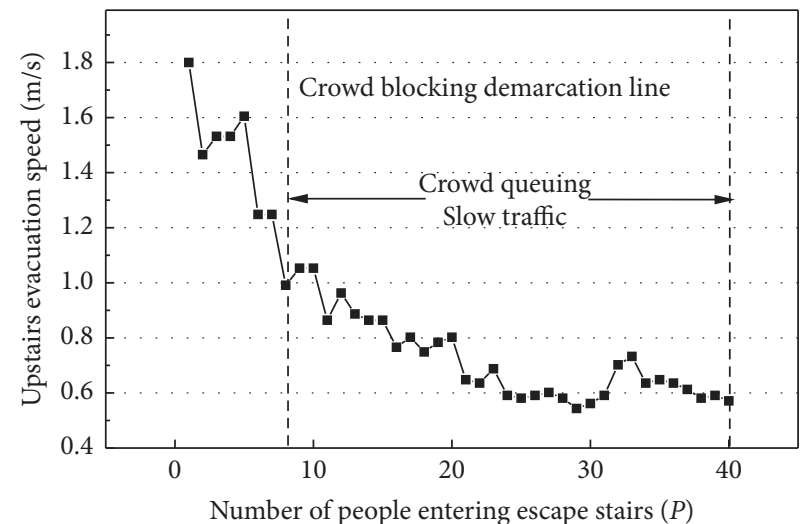

FIgURE 8: Curve of personnel upstairs speed.

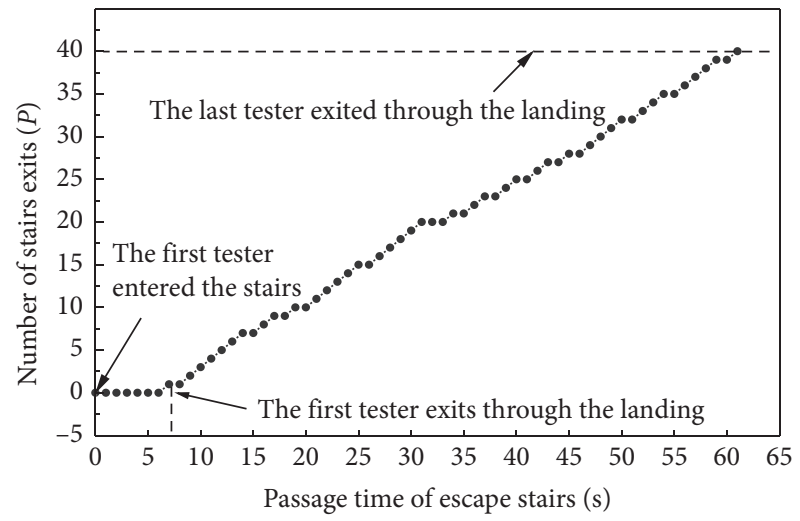

FIGURE 9: Curve of staircase passing time with the exit passing number (under $50 \mathrm{~m}$ staircases spacing).

time). With the assumption that the observed is the farthest from the escape stairs entrance and the man reaches the stair entrance at the speed of a road evacuation, the calculation model of the 3-stage net evacuation time $t_{3}$ ignoring the length of the queued crowd is expressed as follows:

$$
t_{3}=t_{r}+t_{w}+t_{s}
$$

In the equation, 


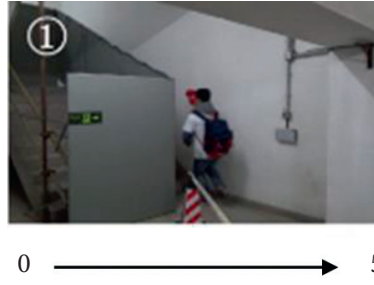

Arrival
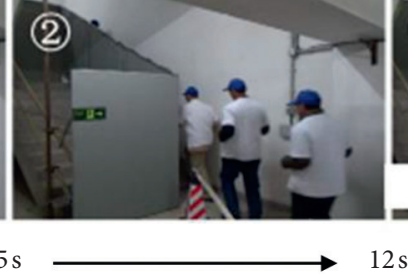

Smooth pass
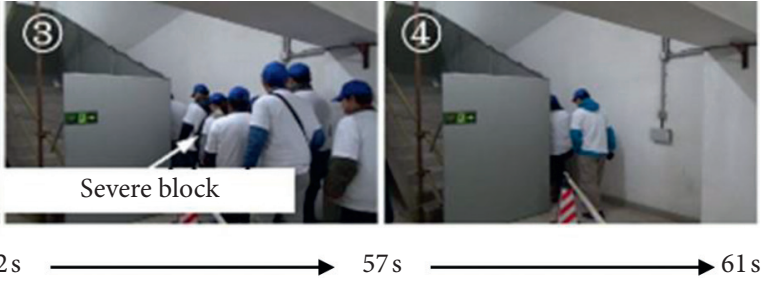

Crowd queue

Congestion dissipates

FIGURE 10: Changing process of crowd flow in front of escape staircase.

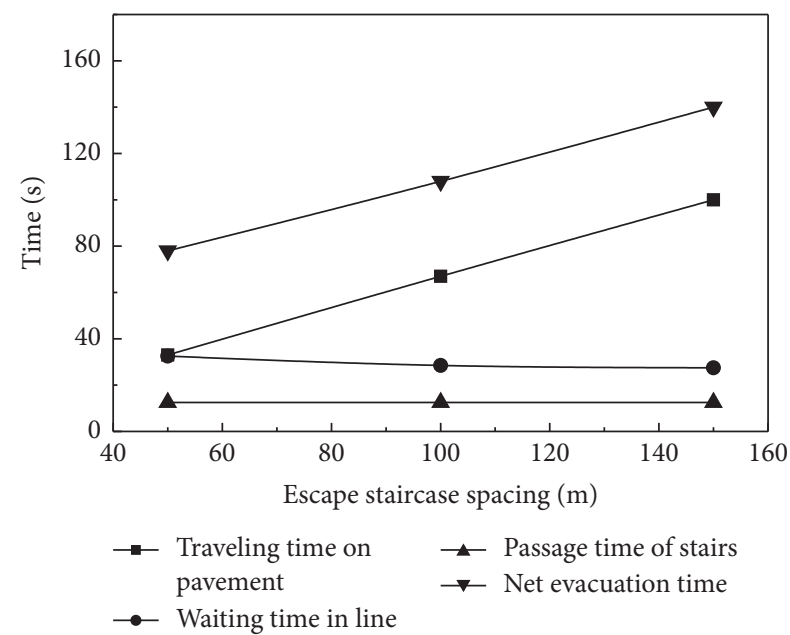

FIGURE 11: Relationship between various evacuation times and escape stair spacing.

$$
\begin{aligned}
& t_{r}=\frac{S}{v_{p}}, \\
& t_{w}=\frac{\alpha N}{Q}, \\
& t_{s}=\frac{L}{v_{c}},
\end{aligned}
$$

where $S$ is the escape stairs spacing $(\mathrm{m}) ; v_{p}$ is the pavement evacuation speed $(\mathrm{m} / \mathrm{s}) ; \alpha$ is the coefficient of the queuing crowd, which is the ratio of the number of people waiting in line when the observed arrives at the escape stairway entrance to the total number of people $(N)$ and affected by the escape capacity of stairs $(Q)$ and the length of the escape stair spacing; $L$ is the distance required to go upstairs $(\mathrm{m}) ; v_{c}$ is the speed of going upstairs during the evacuation in line $(\mathrm{m} / \mathrm{s})$.

In fact, the number of people in the fire-affected area is not independent of the escape stair spacing. Assuming that the number of lanes in the one-way road is $n$; the parking spacing is $s(\mathrm{~m})$; the length of the vehicle is $4.5 \mathrm{~m}$; the average number of passengers on vehicles is $q(P)$, the number of people in the fire-affected area can be estimated by the following equation:

$$
N=\frac{n S q}{s+4.5}
$$

Net evacuation time of personnel can be expressed as follows:

$$
t_{3}=\frac{S}{v_{p}}+\frac{\alpha n S q}{(s+4.5) Q}+\frac{L}{v_{c}} .
$$

According to the guidelines, Equation (1), $t_{3}$ needs to meet the following formula:

$$
t_{3} \leq\left[t_{3}\right]=\operatorname{ASET}-t_{1}-t_{2}=135 s
$$

where $\left[t_{3}\right]$ is the allowable value of net evacuation time; according to section $2, \mathrm{ASET}=6 \mathrm{~min}, t_{1}=2 \mathrm{~min}, t_{2}=105$.

5.2. Calculation Model of Escape Stair Spacing. Based on test results, when the stairway capacity is constant, the shorter the queue waiting time of the observed is, the longer the effective evacuation time is. To minimize queuing people, it is required that the time taken for people passing through the stairs is equal to the traveling time passing through per parking spacing:

$$
\frac{n q_{0}}{Q}=\frac{s+4.5}{v_{p}},
$$

where $q_{0}$ is the number of passengers in the vehicle with no one waiting in line when the parking spacing is certain. When the actual number of passengers in the vehicle $q$ is more than $q_{0}$, the crowd will gather at the entrance of the stairs. The number of people in front of the observed will accumulate constantly with the increase of escape stair spacing and can be expressed approximately by the following equation:

$$
N_{\alpha}=n\left(q-q_{0}\right) \frac{S}{s+4.5} .
$$

Dividing equation (8) by Eequation (4) gives the following:

$$
\alpha=1-\frac{(s+4.5) Q}{n q v_{p}} .
$$

The formula for calculating the escape stair spacing is obtained by equations (5), (6), (9):

$$
S=\frac{Q(s+4.5)\left(\left[t_{3}\right]-L / v_{c}\right)}{n q} \text {. }
$$


TABLE 4: Evacuation note time and cumulative evacuation time under different escape staircase spacing.

\begin{tabular}{|c|c|c|c|}
\hline Escape staircase spacing $(\mathrm{m})$ & 50 & 100 & 150 \\
\hline Calculated value of walking time on pavement (s) & 33 & 67 & 100 \\
\hline Calculated value of the time while waiting in line $(\mathrm{s})$ & $0 \sim 61$ & $0 \sim 128$ & $0 \sim 185$ \\
\hline Calculated value of the time taken for getting through stairs (s) & 12.5 & 12.5 & 12.5 \\
\hline Calculated value of the net evacuation time of personnel $t_{3}(\mathrm{~s})$ & $36 \sim 107.5$ & $60 \sim 203$ & $84 \sim 298$ \\
\hline Trial value of net evacuation time of personnel $t_{3}(\mathrm{~s})$ & 78 & 108 & 140 \\
\hline
\end{tabular}

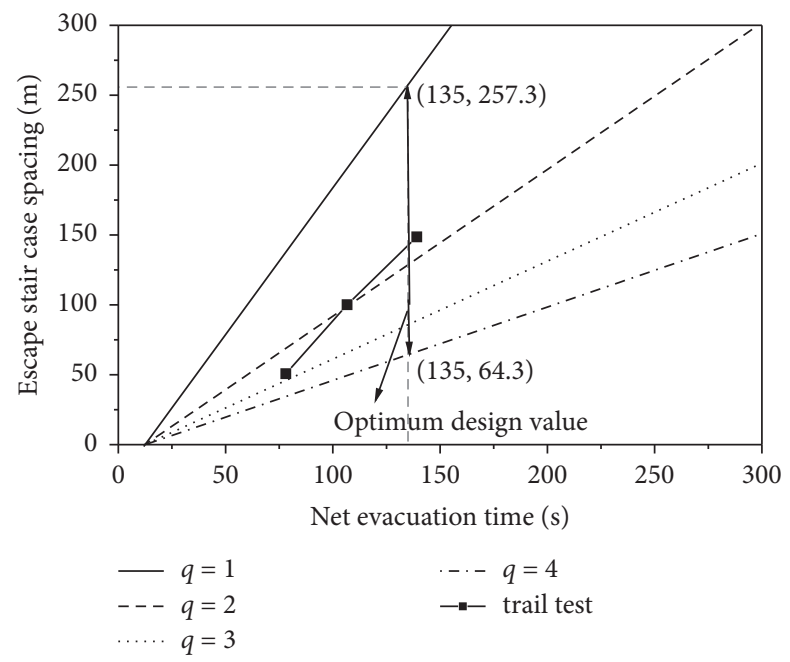

FIGURE 12: Escape stair spacing design curve.

TABLE 5: Project cases of up and down escape staircase $[18,19]$.

\begin{tabular}{|c|c|c|c|}
\hline Name of the tunnel & $\begin{array}{l}\text { Diameter of the } \\
\text { tunnel }(\mathrm{m})\end{array}$ & Number of lanes & Structure of escape stairs \\
\hline $\begin{array}{l}\text { Nanjing Weisan road } \\
\text { tunnel }\end{array}$ & 14.5 & $\begin{array}{l}\text { Double pipes, double layer } \\
\text { eight traffic lanes }\end{array}$ & $\begin{array}{c}\text { Set a group of escape stairs every } 64 \mathrm{~m} \text {, the width of the } \\
\text { step of the stair is } 0.8 \mathrm{~m}\end{array}$ \\
\hline $\begin{array}{l}\text { Anghai Jungong road } \\
\text { tunnel }\end{array}$ & 14.5 & $\begin{array}{l}\text { Double pipes, double layer } \\
\text { eight traffic lanes }\end{array}$ & $\begin{array}{c}\text { Set a group of escape stairs every } 80 \mathrm{~m} \text {, the width of the } \\
\text { step of the stair is } 0.8 \mathrm{~m}\end{array}$ \\
\hline $\begin{array}{l}\text { Hanghai Shangzhong road } \\
\text { tunnel }\end{array}$ & 14.5 & $\begin{array}{l}\text { Double pipes, double layer } \\
\text { eight traffic lanes }\end{array}$ & $\begin{array}{l}\text { Set a group of escape stairs every } 100 \mathrm{~m} \text {, the width of } \\
\text { the step of the stair is } 0.8 \mathrm{~m}\end{array}$ \\
\hline $\begin{array}{l}\text { Yangzhou slender west } \\
\text { lake tunnel }\end{array}$ & 14.5 & $\begin{array}{l}\text { Single pipe, double layer eight } \\
\text { traffic lanes }\end{array}$ & Set a group of escape stairs every $100 \mathrm{~m}$ \\
\hline Shanghai bund tunnel & 13.9 & $\begin{array}{l}\text { Single pipe, double layer six } \\
\text { traffic lanes }\end{array}$ & Set a group of escape stairs every $100 \mathrm{~m}$ \\
\hline
\end{tabular}

5.3. Comparison and Verification between Theory and Experiment. According to the simulated test, evacuation parameters such as $v_{p}=1.5 \mathrm{~m} / \mathrm{s}, Q=0.7 \mathrm{P} / \mathrm{s}, t_{s}=12.5 \mathrm{~s}$ were obtained. In addition, considering test parameters $s=1.5 \mathrm{~m}, n=2$, and $q=(1 \sim 4) P$, calculated values of the traveling time on pavement, the waiting time in line, the passage time of stairs, and the net evacuation time were calculated based on the above-mentioned theory. As shown in Table 4, all test values of net evacuation times are within the calculated value range.

Based on the proposed method and experiment results, design curves of the escape stair spacing with different $q$ were obtained. As shown in Figure 12, the test value gradually shifts to a curve of $q=1$ as the escape stair spacing increases. The possible reason is the number of people remains unchanged when the escape staircase spacing is 100 and $150 \mathrm{~m}$, the equivalent number of people on a car decreases, so the net evacuation time decreases and falls outside the curve of $q=2$, especially for the escape staircase spacing of $150 \mathrm{~m}$. The escape stair spacing with respect to the allowed net evacuation time under this test scenario was calculated to be $64.3 \sim 257.3 \mathrm{~m}$, and considering the most unfavorable situation, the optimal escape stair spacing should be set to $64.3 \mathrm{~m}$. Compared with the project cases of up and down escape staircase, as shown in Table 5, the escape stair spacing of Nanjing Weisan Road Tunnel is basically consistent with the theoretical value, but the escape stair spacing of other tunnels is generally larger, which means that there is a security risk to some degree. 


\section{Conclusions}

To relate evacuation basic parameters and reasonable staircase spacing of up and down escape staircase in case of fire, an evacuation experiment, which was based on the most unfavorable evacuation scenario, was conducted. Based on the experiment, a calculation model of three-phase personnel net evacuation time was established. By simplifying the evacuation model, a calculation formula of the reasonable escape stair spacing considering the influence of multiple factors was proposed. And the theoretical model was applied to project cases of up and down escape staircase and verified. But this study did not quantify the impact of psychological panic and randomness of evacuees on evacuation behavior, so further research will be carried out in the future. The main findings of the studies are as follows:

(1) In the emergency state, the observed value of evacuation speed of the crowd walking in the tunnels is between 1.43 and $1.95 \mathrm{~m} / \mathrm{s}$, which is greatly affected by gender and age. Specifically, the evacuation speed of males is higher than that of females, and the evacuation speed of the young and middle-aged population is faster. The observed value of evacuation speed of the crowd going upstairs is between 0.5 and $1.1 \mathrm{~m} / \mathrm{s}$. After the phenomenon of queuing in the staircase appears, there will be a continuous stream of people, and the individual characteristics will become weak. There is not much difference in the speed of going upstairs between different types of people as well.

(2) The mean of the observed value of traffic capacity of escape stairs with $0.8 \mathrm{~m}$ net width is $0.7 \mathrm{P} / \mathrm{s}$, and the stream of people can only move forward in a singlestranded way. The entrance of the stairs is the bottleneck in the process of the evacuation of the entire stairs. The crowds there are extremely prone to be overstocking, contributing to cluster accidents due to the blockage of people. Therefore, it is necessary to strengthen the orderly guidance to the people at the entrance of stairs through broadcasting. The net evacuation time of the crowd increases linearly with the increasing escape stair spacing, and the walking time on pavement and waiting in line take a relatively major proportion.

(3) A three-stage calculation model of net evacuation time was established. The theoretical calculation equation of the net evacuation time on the escape stair spacing, traffic capacity of stairs, and the number of evacuees was proposed as well. Based on this, by simplifying the crowd evacuation model, further considering the queuing effect, the number of people on the pavement, the parking space, and the capacity of the escape stairs, a reasonable formula for calculating the escape staircase spacing was proposed.

(4) The results of theoretical calculation and experimental observation were compared and analyzed, and the optimal escape stair spacing under this test scenario is calculated to be $64.3 \mathrm{~m}$ considering the worst case of $q=4 \mathrm{P}$, which is generally smaller than the set value of escape stair spacing of existing double layer tunnels except for Nanjing Weisan Road Tunnel.

\section{Data Availability}

All the data, models, and codes generated or used during the study are included in the manuscript.

\section{Conflicts of Interest}

The authors declare that they have no conflicts of interest.

\section{Acknowledgments}

This work was supported by National Natural Science Foundation "Joint Fund Project" (No. U1834208).

\section{References}

[1] DG-TJ08-2033-2008, Rode Tunnel Design Code, DG-TJ082033-2008, Shanghai, China, 2008, in Chinese.

[2] W. S. Liu, "“Personnel evacuation simulation analysis and safety assessment of Shanghai Yangtze tunnel." (in Chinese)," Underground Engineering and Tunnels, no. 2, pp. 6-9+17+56, 2011.

[3] P. H. Zhang, M. C. Yu, and J. Song, "Optimizing analysis on escape stair spacing for downward longitudinal evacuation in road tunnel," Shenyang Jianzhu University (Natural Science), vol. 30, no. 4, pp. 688-694, 2014, in Chinese.

[4] J. A. Capote, D. Alvear, O. Abreu, A. Cuesta, and V. Alonso, "A real-time stochastic evacuation model for road tunnels," Safety Science, vol. 52, pp. 73-80, 2013.

[5] M. Seike, N. Kawabata, and M. Hasegawa, "Evacuation speed in full-scale darkened tunnel filled with smoke," Fire Safety Journal, vol. 91, pp. 901-907, 2017.

[6] L. C. Boer, D. W. Veldhuijzen, and V. Zanten, Behaviour on Tunnel Fire, pp. 91-98, Springer, Berlin, Germany, 2007.

[7] D. Nilsson, M. Johansson, and H. Frantzich, "Evacuation experiment in a road tunnel: a study of human behaviour and technical installations," Fire Safety Journal, vol. 44, no. 4, pp. 458-468, 2009.

[8] K. Fridolf, K. Andrée, D. Nilsson, and H. Frantzich, "The impact of smoke on walking speed," Fire and Materials, vol. 38, no. 7, pp. 744-759, 2013.

[9] M. Seike, N. Kawabata, and M. Hasegawa, "Quantitative assessment method for road tunnel fire safety: development of an evacuation simulation method using cfd-derived smoke behavior," Safety Science, vol. 94, pp. 116-127, 2017.

[10] E. Ronchi, K. Fridolf, H. Frantzich et al., "A tunnel evacuation experiment on movement speed and exit choice in smoke," Fire Safety Journal, vol. 97, pp. 126-136, 2017.

[11] Y.-c. Zhang, A. Zhou, Y. Xiang et al., "Evacuation experiments in vertical exit passages in an underwater road shield tunnel," Physica A: Statistical Mechanics and Its Applications, vol. 512, pp. 1140-1151, 2018.

[12] Z. Fang, J. P. Yuan, and Z. Zhang, "Evacaution pattern of city underwater tunnel and result analysis of evacuation drill. (in Chinese)," Fire Science and Technology, vol. 27, no. 10, pp. 746-749, 2008. 
[13] B. Xie, S. Zhang, Z. Xu, L. He, B. Xi, and M. Wang, "Experimental study on vertical evacuation capacity of evacuation slide in road shield tunnel," Tunnelling and Underground Space Technology, vol. 97, p. 103250, 2020.

[14] Y. C. Zhang, Y. Xiang, C. He, D. Zhang, and Y. Tang, " "Experimental study on pedestrian behavior and traffic capacity of cross passage in highway tunnel." (in Chinese)," Journal of Southwest Jiaotong University, vol. 51, no. 04, pp. 615-620, 2016.

[15] Q. Zhou, H. B. Xu, and C. X. Xing, “"Experimental study on the pass rate of cross aisle of highway tunnel." (in Chinese)," Fire Science and Technology, vol. 35, no. 7, pp. 939-941, 2016.

[16] W. H. Cao and Q. Shen W, Design of Extra-diameter and Overlength Shiel Tunnel-The Shanghai Yangtze River Tunnel, China Building Industry Press, Beijing, China, 2010, in Chinese.

[17] A. Noren and J. Winer, Modelling Crowd Evacuation from Road and Train Tunnels-Data and Design for Faster Evacuations, Lund University, Lund, Sweden, 2003.

[18] Y. Z. Hu, “"On an innovation of tunnel cross section design of double-deck \& double-direction shield method." (in Chinese)," China Municipal Engineering, vol. 149, pp. 1-3, 2010.

[19] C. J. Qiao, X. H. Guo, and X. H. Ke, "Design of nanjing weisan road tunnel," Wuhan Investigation \& Design, no. 6, pp. 53-57+46, 2011. 